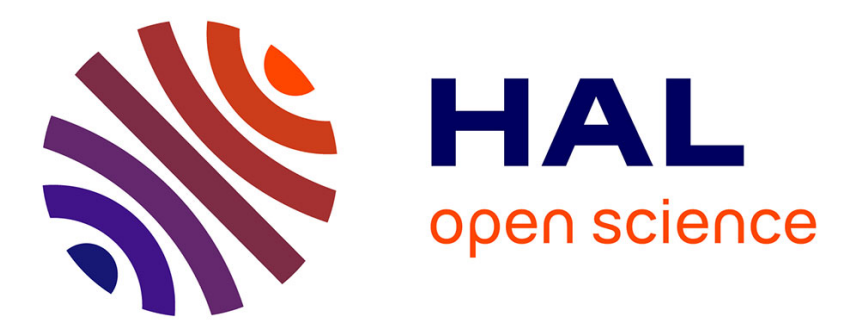

\title{
Charge density research: from inorganic and molecular materials to proteins
}

\author{
Claude Lecomte, Emmanuel Aubert, Vincent Legrand, Florence Porcher, \\ Sébastien Pillet, Benoît Guillot, Christian Jelsch
}

\section{To cite this version:}

Claude Lecomte, Emmanuel Aubert, Vincent Legrand, Florence Porcher, Sébastien Pillet, et al.. Charge density research: from inorganic and molecular materials to proteins. Zeitschrift für Kristallographie - Crystalline Materials, 2005, 220 (4), pp.373-384. 10.1524/zkri.220.4.373.61623 . hal01005856

\section{HAL Id: hal-01005856 \\ https://hal.science/hal-01005856}

Submitted on 21 Feb 2017

HAL is a multi-disciplinary open access archive for the deposit and dissemination of scientific research documents, whether they are published or not. The documents may come from teaching and research institutions in France or abroad, or from public or private research centers.
L'archive ouverte pluridisciplinaire $\mathbf{H A L}$, est destinée au dépôt et à la diffusion de documents scientifiques de niveau recherche, publiés ou non, émanant des établissements d'enseignement et de recherche français ou étrangers, des laboratoires publics ou privés. 


\title{
Charge density research: from inorganic and molecular materials to proteins
}

\author{
Claude Lecomte, Emmanuel Aubert, Vincent Legrand, Florence Porcher, Se'bastien Pillet, Benô^t Guillot \\ and Christian Jelsch \\ Laboratoire de Cristallographie et Modélisation des Matériaux Minéraux et Biologiques, UMR CNRS 7036, Université Henri Poincaré, Nancy I \\ - Faculté des Sciences et Techniques - BP 239, 54506 Vandœuvre-lès-Nancy Cedex, France
}

Electron density / Photocrystallography / Porous materials / Molecular magnetic materials / Protein refinement

\begin{abstract}
This paper intends to present applications of experimental charge density research in physics, chemistry and biology. It describes briefly most methods for modelling the charge density and calculating and analyzing derived properties (electrostatic potential, topological properties). These methods are illustrated through examples ranging from material science and coordination chemistry to biocrystallography, like the estimation of electrostatic energy in a zeolite-like material or the relation between electrostatic energy and spin density to macroscopic magnetic properties in a ferrimagnetic molecular material. The accurate structure and charge density of a coordination compound exhibiting LIESST effect is also described, together with an exemple of transferability of charge density methods to macromolecular science and protein crystallography.
\end{abstract}

\section{Introduction}

Due to its great success in chemistry, physics, material science, mineralogy and biology, small molecule crystallography appears more and more as a very powerful technique to solve structural problems [1] rather than a major scientific area. The "products" offered by crystallographers to non crystallographers seem to be so easy to use that many colleagues do believe that crystallography is not a science anymore; crystallography is a victim of its own success and many university professors do believe that crystallographic research cannot exist, particularly in small molecule crystallography. In fact, due to the new computing facilities, to modern technologies and to new X-ray sources (synchrotron, plasma pulse X-ray sources, ... [2]), crystallography appears as a new science which brings much accurate information unattainable by other techniques. Among them, charge density and high resolution crystallography allow precise electronic structure determination of crystals and molecules in their ground state [3] and soon in excited states $[4,5]$. Charge density research is now a mature field that is available to perform studies in chemistry, physics, material science and biology: on the experimental side, the ability to collect accurate X-ray diffraction data quickly using two-dimensional CCD detectors [6] has opened this field to many small-molecule crystallographers; the availability of user-friendly softwares (XD [7], MOPRO [8] ...) more easily permits accurate charge density analysis and allows calculation of derived properties (charges, atomic moments, electrostatic potential and field, electrostatic energy, ...), even for scientists entering the field.

The aim of this paper is to show the possibilities and strength of this method by selecting a few examples ranging from inorganic materials to proteins, including organic molecules and coordination compounds.

\section{Electron density modelling, topological properties and electrostatic properties}

\section{The multipole model}

Modelling of valence charge density requires accurate $\mathrm{X}$ ray diffraction intensities [6,9-10]. In the present article, mainly devoted to the work performed recently in $\mathrm{LCM}^{3} \mathrm{~B}$, the charge density models fitted by least-squares to the X-ray data are due to Stewart [11] and Coppens and co-workers [12-13]. In the Kappa formalism [12], the estimation of the net atomic charge and of the expansion/ contraction of the perturbed valence density (spherical average) are described by:

$$
\varrho_{\text {stat }}^{\text {at }}(r)=\varrho_{\text {core }}^{\text {at }}(r)+P_{\text {val }} \kappa^{3} \varrho_{\text {val }}^{\text {at }}(\kappa r)
$$

where $\varrho_{\text {core }}^{\text {at }}(r)$ and $\varrho_{\text {val }}^{\text {at }}(\kappa r)$ are the spherically averaged core and valence electron densities of the free atom, calculated from the best available wave functions. $P_{\text {val }}$ is the valence shell population and $\kappa$ is the expansion $(\kappa<1)$ or contraction $(\kappa>1)$ coefficient of the perturbed density.

To take into account the non-spherical shape of the valence-electron distribution, multipole parameters [13, 14] 
can be added to the Kappa model. Then, the pseudo-atomic density is written:

$$
\begin{aligned}
\varrho_{\text {stat }}^{\text {at }}(\boldsymbol{r})= & \varrho_{\mathrm{core}}^{\text {at }}(r)+P_{\mathrm{val}} \kappa^{3} \varrho_{\mathrm{val}}^{\text {at }}(\kappa r) \\
& +\sum_{l=0}^{l_{\max }} \kappa^{\prime 3} R_{l}\left(\kappa^{\prime} r\right) \sum_{m=0}^{l} P_{l m \pm} y_{l m \pm}(\theta, \varphi)
\end{aligned}
$$

with

$$
\int\left|y_{l m \pm}\right| \mathrm{d} \Omega=2 \quad \text { if } \quad l \neq 0 \text { and } 1 \text { if } l=0
$$

where $y_{l m \pm}$ are the spherical harmonic angular functions in real form, and

$$
R_{l}=N_{l} r^{n} \exp -(\xi r)
$$

are Slater-type radial functions in which $N_{l}$ is a normalization factor. The $P_{l m \pm}$ are the multipoles coefficients which are refined in the least squares process. The normalization of $y_{l m \pm}$ implies that a $P_{l m \pm}$ value of +1 transfers one electron from the negative lobe of the $y_{l m \pm}$ function to the positive lobe. The $\zeta$ parameters are initially chosen to be consistent with atom optimized orbital exponents $\alpha$ $\left(\xi=2 \alpha\right.$ since $\left.\varrho(r) \propto \psi^{2}\right)$. The $n$ exponents of the Slater function are chosen with $n \geq l$ for proper Coulombic behaviour satisfying Poisson's equation as $r$ goes to zero. The local axes on each atom are defined by the program user; this flexibility is very valuable for large molecules like proteins possessing non-crystallographic local symmetry and/or containing chemically equivalent atoms when one wants to reduce the number of the $\kappa, P_{\mathrm{val}}, P_{l m \pm}$ electron-density parameters in the least squares process.

\section{Charge density maps}

Static deformation density maps are computed by summing the static pseudo-atoms deformation densities over all $N_{\text {at }}$ individual atoms (Eq. 5)

$$
\Delta \varrho_{\text {stat }}(\boldsymbol{r})=\sum_{j=1}^{N_{\text {at }}} \delta \varrho_{\text {stat }}^{j}\left(\boldsymbol{r}-\boldsymbol{r}_{j}\right)
$$

where

$$
\begin{aligned}
\delta \varrho_{\mathrm{stat}}^{j}(\boldsymbol{r})= & P_{\mathrm{val}}^{j} \kappa^{3} \varrho_{\mathrm{val}}^{j}(\kappa r)-N \varrho_{\mathrm{val}}^{j}(r) \\
& +\sum_{l=0}^{l_{\max }} \kappa^{\prime 3} R_{l}^{j}\left(\kappa^{\prime} r\right) \sum_{m=0}^{l} P_{l m \pm}^{j} y_{l m \pm}(\theta, \varphi)
\end{aligned}
$$

$N$ being the number of valence electrons of the corresponding free atom.

These maps represent the redistribution of electron density due to interatomic interactions using as reference state the Independent Atom Model (IAM). An example of the static deformation charge density of a nitronyl ring, consisting of two nitroxide $\mathrm{NO}^{*}$ functions, in the free radical NitPy [15] is given in Fig. 1. Density maxima are located on the bonds and $\mathrm{O}$ lone pairs; in this latter case, they are perpendicular to the $\mathrm{N}-\mathrm{O}$ axis contrary to what is typically observed in $\mathrm{C}=\mathrm{O}$ groups, owing to their different hybridization states $\left(\mathrm{sp}^{2}\right.$ in $\mathrm{C}=\mathrm{O}, p_{z}$ in $\mathrm{N}-\mathrm{O}$ ). The charge density depletions around the oxygen and nitrogen atoms are a signature of the deformation density of a $\mathrm{NO}^{*}$ radical [15].

Such deformation maps are computed and discussed in most charge density papers (see, for example, [16-18])

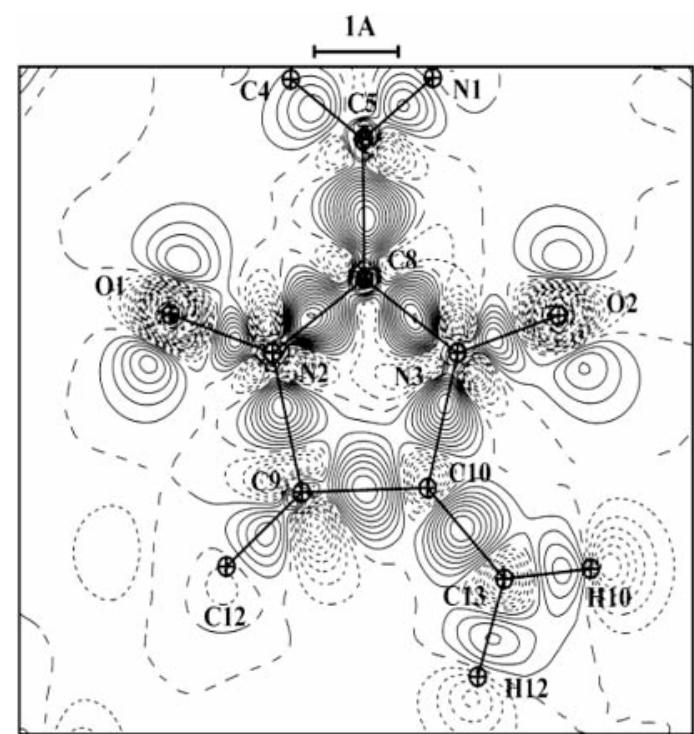

Fig. 1. Static deformation density of a nitronyl-nitroxide group in NitPy [15]. The contour interval is $0.05 \mathrm{e} \AA^{-3}$; positive contours are shown as solid lines, negative and zero contours as dashed lines.

but are gradually being replaced by gradient and Laplacian maps derived from the topological analysis of total static charge density. These latter are obtained without any reference to a given free or prepared atom state [19].

\section{Topology of the electron density: application to atom-atom interactions}

Bader developed a method [19] based on the topology of the total electron density that leads to an atomic definition of the properties of matter: "the form of the total electron distribution in a molecule is the physical manifestation of the forces acting within the system" [19]. The characteristics of the total electron density topology may be analyzed by a search of the critical points (minima, maxima and saddle points) located at given points $\boldsymbol{r}_{\mathrm{CP}}$ where the gradient of the density is null:

$$
\operatorname{Grad}\left(\varrho\left(\boldsymbol{r}_{\mathrm{CP}}\right)\right)=0 .
$$

At that point, diagonalization of the Hessian matrix, whose elements are:

$$
H(i, j)=\frac{\partial^{2} \varrho}{\partial x_{i} \partial x_{j}}
$$

yields as eigenvalues $\lambda_{i},(i=1,3)$ the curvatures and eigenvectors the principal axes of curvature. Whether a function is a minimum or a maximum is determined by the sign of $\lambda_{i}$, at this point. The trace of the Hessian matrix is the Laplacian of the density, which is an invariant.

$$
\nabla^{2} \varrho=\operatorname{Grad} \bullet \operatorname{Grad}(\varrho)=\sum_{i=1}^{3} \frac{\partial^{2} \varrho}{\partial x_{i}^{2}} .
$$

In regions of space where the Laplacian is negative, the electronic charge is concentrated; conversely charge depletion regions are characterized by positive Laplacian values.

The critical points are characterized by the numbers of non zero eigenvalues of $H, \omega$ and by the signature $\sigma$, algebraic sum of the signs of the eigenvalues. Generally, the 
rank $\omega$ is 3 and four types of critical points $(\omega, \sigma)$ are defined:

- $((3,+3)$ critical point $)$ : the electron density at that point is a local minimum (three positive curvatures). Such a point is found, for example, in the center of a cage;

- $((3,-3)$ critical point $)$ : the electron density at that point is a local maximum (three negative curvatures); Such points are usually found at nuclei positions;

- $((3,+1)$ critical point $)$. The density is minimum in the plane containing the two positive curvatures and maximum in the perpendicular direction. This type of critical point is found at the center of a ring formed by $n$ bonded atoms.

- $((3,-1)$ critical point $)$. The density is maximum in the plane containing the two negative curvatures and minimum along the perpendicular line (bond path). These critical points are characteristic of interatomic bonds.

The Laplacian of the electron density (Eq. (9)) is also related to the energy density by the virial theorem. The sign of the Laplacian determines whether the kinetic or potential energy density is in excess in the total energy density. In regions of space where the Laplacian is positive, the total energy density is dominated by the kinetic energy density (hydrogen bonds, ionic bonds ...) and the electron density is locally depleted. These bonds can be classified as closed shell interactions. As a contrary, in regions where the Laplacian is negative and electronic charge is concentrated, the potential energy density dominates, as in the case of lone pairs and covalent bonds.

In this latter case, the positive curvature $\lambda_{3}$ is associated with the direction joining the two atoms covalently bonded, i.e. the bond path, and the $\lambda_{1}, \lambda_{2}$ curvatures define the ellipticity of the bond according to:

$$
\varepsilon=\left|\frac{\lambda_{1}-\lambda_{2}}{\lambda_{2}}\right| \text {. }
$$

For example, $\varepsilon$ would increase with the $\pi$ character of a double bond, but will go to zero for a triple bond.

The topology of the total density allows a new definition of atoms in a molecule through partition into atomic basins $\Omega$ (Eq. (11)) whose boundary surface satisfies:

$$
\operatorname{Grad} \varrho(r) \cdot n=0
$$

where $\boldsymbol{n}$ is a unit vector locally perpendicular to the surface.

Atomic moments $m_{n}$ of order $n$ like charges $(n=0)$ or dipole moments $(n=1)$ are calculated by integration over the atomic basin $\Omega$ according to:

$$
m_{n}=\int_{\Omega} r^{n} \varrho(\boldsymbol{r}) d^{3} \boldsymbol{r} .
$$

\section{Electrostatic properties}

The total electrostatic potential at a point $\boldsymbol{r}$ can be calculated directly from the multipolar model:

$$
V(\boldsymbol{r})=V_{\text {core }}(\boldsymbol{r})+V_{\mathrm{val}}(\boldsymbol{r})+\Delta V(\boldsymbol{r})
$$

with

$$
V_{\text {core }}(\boldsymbol{r})=\frac{Z}{|\boldsymbol{r}-\boldsymbol{R}|}-\int \frac{\varrho_{\text {core }}\left(\boldsymbol{r}^{\prime}\right) d^{3} \boldsymbol{r}^{\prime}}{\left|\boldsymbol{r}-\boldsymbol{R}-\boldsymbol{r}^{\prime}\right|}
$$

and

$$
V_{\mathrm{val}}(\boldsymbol{r})=-\int \frac{\varrho_{\mathrm{val}}\left(\boldsymbol{r}^{\prime}\right) d^{3} r^{\prime}}{\left|\boldsymbol{r}-\boldsymbol{R}-\boldsymbol{r}^{\prime}\right|}
$$

$\Delta V$ is the deformation potential which can be calculated in direct space to get the potential of a molecule removed from the crystal lattice (for explicit formulation, see [20]).

According to Stewart, who is one of the pioneers in the field [21], $V(\boldsymbol{r})$ can also be calculated in reciprocal space leading to the crystal potential:

$$
V(\boldsymbol{r})=V_{\mathrm{IAM}}(\boldsymbol{r})+\Delta V(\boldsymbol{r})+V_{o}
$$

with

$$
\begin{aligned}
\Delta V(\boldsymbol{r})= & (\pi V)^{-1} \sum_{\boldsymbol{H}} H^{-2}\left(\left|F_{m}\right| \mathrm{e}^{i \phi_{m}}-\left|F_{s}\right| \mathrm{e}^{i \phi_{s}}\right) \\
& \times \exp (-2 \pi i \boldsymbol{H} \cdot \boldsymbol{r})
\end{aligned}
$$

and

$$
V_{\mathrm{IAM}}(\boldsymbol{r})=-\int \frac{\varrho_{\mathrm{IAM}}(\boldsymbol{r})}{\left|\boldsymbol{r}-\boldsymbol{r}^{\prime}\right|} d^{3} \boldsymbol{r}^{\prime}
$$

where the suffixes $m$ and $s$ denote multipolar and IAM contributions. $V_{\text {IAM }}$ converges rapidly and is calculated in direct space using a cluster of crystal unit cells.

The electrostatic potential in molecular crystals can be used to generate an experimental force field for molecular modelling: atomic and/or fragments multipole moments and charges can be fitted to the experimental potential as shown by Ghermani et al. [20, 22 and references therein]. These quantities can be more adequate than theoretical charges calculated from free molecules in vacuum when solid state problems are concerned (because they include crystal field effects) despite experimental systematic errors, in peculiar when considering $\mathrm{H}$ atoms.

The calculation of electrostatic intermolecular energies from X-ray experiments is in principle straight forward as soon as both charges and potential are known according to:

$$
E_{\mathrm{A} / \mathrm{B}}=\int \varrho_{\mathrm{A}}(\boldsymbol{r}) V_{\mathrm{B}}(\boldsymbol{r}) d^{3} \boldsymbol{r}
$$

where $\mathrm{A}$ and $\mathrm{B}$ are the interacting entities [23-25].

An example concerning the estimation of the electrostatic interaction energy in porous materials is given below [26].

\section{Topographic analysis of the electrostatic potential}

Recently, the topographic analysis of $V(\boldsymbol{r})$ has been introduced in experimental charge density research [27-33]. While the shape and extent of the positive (electrophilic) and negative (nucleophilic) electrostatic potential regions surrounding a molecule only qualitatively feature the electrostatic interactions, an accurate topographic analysis of the electrostatic potential distribution yields a quantitative estimation of interactions. This method, largely inspired by Bader's theory [19], has been extensively used by many authors [27-33]. 


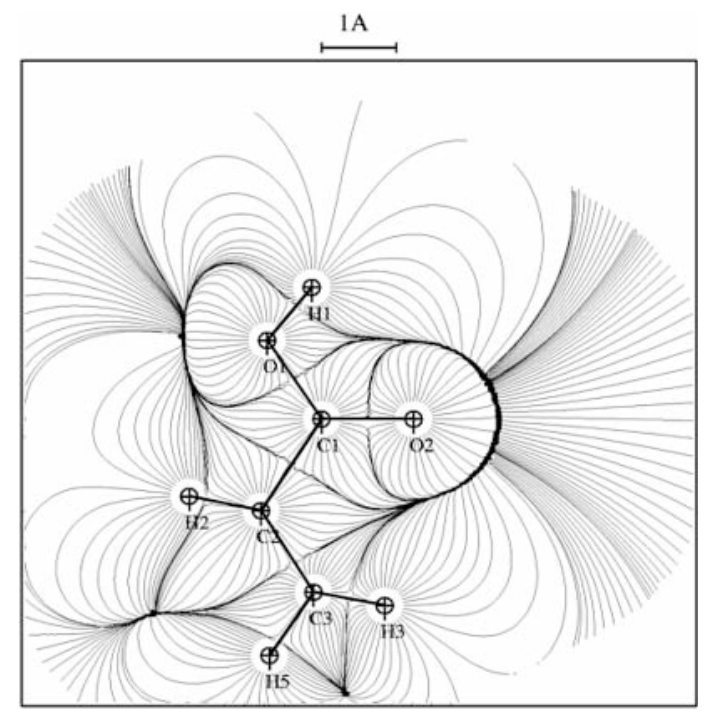

Fig. 2. Electric field lines generated by an ibuprofen molecule extracted from the crystal. The plane corresponds to that of the $\mathrm{COOH}$ group [32].

The topographic analysis of the electrostatic potential $V(\boldsymbol{r})$ is related to the properties of the electric field vector through:

$$
\boldsymbol{E}(\boldsymbol{r})=-\boldsymbol{G r a d}(V(\boldsymbol{r})) .
$$

Following Bader's nomenclature [19], $(3,-1),(3,+1)$ and $(3,+3)$ electrostatic potential CP's are generally considered. $(3,-3)$ CP's correspond to the electrostatic potential maxima located at the nuclei positions (dominant contribution of the positive nuclear charge).

Such methodology has been applied in experimental solid state research by Tsirelson et al. [31], who have determined CP's sites and corresponding bond paths in rocksalt crystals from electron diffraction measurements. In the field of molecular compounds, Bouhmaida et al. [32] have illustrated the electric field line features of the ibuprofen drug molecule after an analytical derivation of experimental electrostatic potential and field by a fit to high-resolution X-ray diffraction data. Figure 2 shows how the gradient vector lines (tangent to the electric field) define closed or extended atomic basins of an isolated ibuprofen molecule. These basins are limited by electric field zero flux surfaces, which satisfy:

$$
\operatorname{Grad}(V(\boldsymbol{r})) \cdot \boldsymbol{n}=0
$$

$\boldsymbol{n}$ being unit vectors perpendicular to those surfaces at each point.

The electric field lines, which are not allowed to cross, give rise to a particular partitioning of the molecule in agreement with the Slater's nuclear screening concept. Furthermore, according to the Gauss's law, the zero-flux surfaces partition the molecule into electrically neutral atomic spaces, in opposite to atomic basins defined from the topological analysis of electron density. In topographic analysis of the potential, the charge transfer inside the molecule is revealed by the size and shape of atomic volumes: an atom like oxygen exhibits the smallest basin volume since the concentration of the electron density screens, and thus weakens, the positive contribution of the nuclear charge. Conversely, positively charged hydrogen atoms display wide basins, especially in the peripheral region of the molecule. As also shown in Fig. 2, $(3,-1)$ saddle CP's, where the electric field (or the electric force strength) vanishes, are found between each pair of nuclei in the molecule. The positions of the CP's are related to the chemical nature of the atoms involved in bonds. In homonuclear $\mathrm{C}-\mathrm{C}$ bonds, the $\mathrm{CP}$ 's are equidistant to each nucleus $(0.76$ and $0.70 \AA$ for single and aromatic bonds, respectively). In heteronuclear $\mathrm{C}-\mathrm{H}(\mathrm{CP}-\mathrm{H}=0.37 \AA$ in both $\mathrm{CH}$ and $\mathrm{CH}_{3}$ groups), $\mathrm{O}-\mathrm{H}(\mathrm{CP}-\mathrm{H}=0.33 \AA)$ and $\mathrm{C}-\mathrm{O}$ bonds $(\mathrm{CP}-\mathrm{O}=0.64$ and $0.61 \AA$ for single and double bonds, respectively), the $(3,-1)$ CP's position depends on the electrostatic balance between the connected nuclei. These atom-CP distances were found in good agreement with the covalent atomic radius values from electrostatic considerations reported by Politzer et al. [33]. On the other hand, four minima of the electrostatic potential corresponding to the $(3,+3) \mathrm{CP}$ 's were localized near the substituted phenyl ring $\left(-0.199\right.$ and $-0.183 \mathrm{e} \AA^{-1}$ up and down the plane) and in the vicinity of the carboxylate $(\mathrm{COOH})$ group $\left(-0.235\right.$ and $\left.-0.314 \mathrm{e}^{-1}\right)$ of the ibuprofen molecule. This example demonstrates how the use of topographic analysis of the electrostatic potential can provide efficient insight into both inner and outer properties of a molecule.

\section{Electrostatic interaction energy in porous materials}

One interesting application of electrostatic potential in inorganic materials concerns zeolite-type materials [34]. The characterization of interactions between porous materials and guest molecules is of primary interest for understanding catalytic properties or confinement effects, leading to interesting physical properties like non linear optics [35].

As a model case, the experimental charge density of the $\mathrm{AlPO}_{4}-15$ [36] molecular sieve has been studied. The structure of $\mathrm{AlPO}_{4}-15$ can be described in the following way: a three dimensional network based on $\mathrm{PO}_{4}$ tetrahedra

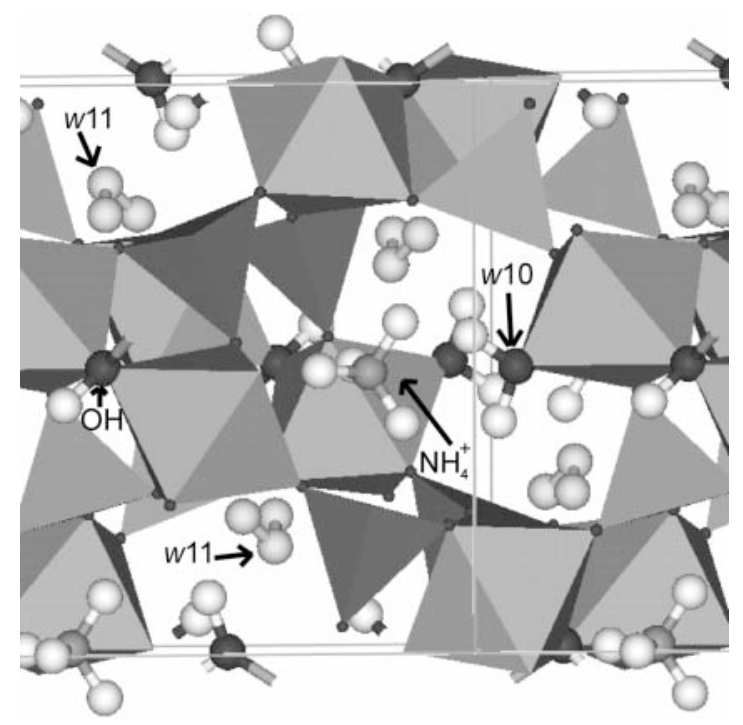

Fig. 3. Crystal structure of $\mathrm{AlPO}_{4}-15$. 


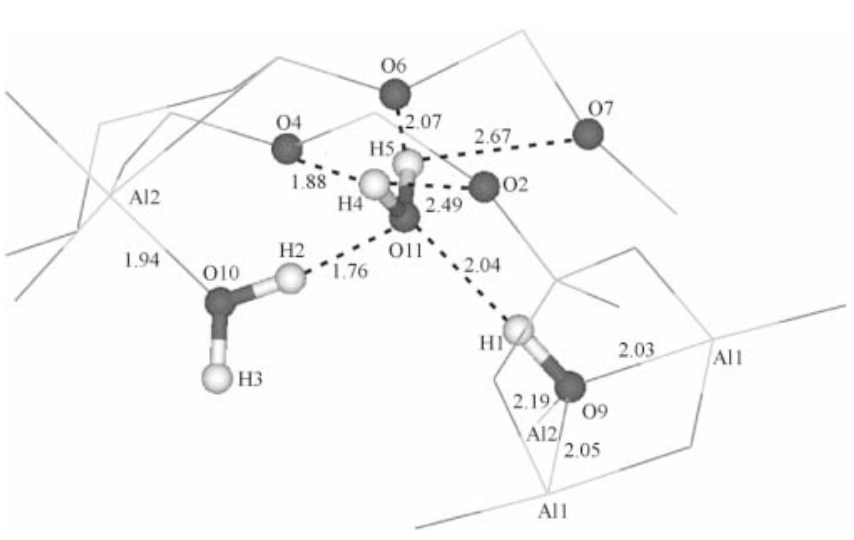

Fig. 4. Interaction of the water molecules and of the hydroxyl group $\left(\mathrm{O}_{9} \mathrm{H}_{1}\right)$ with the AlPO framework; distances are given in $\AA$.

linked to $\mathrm{AlO}_{6}$ octohedra exhibits channels filled with a hydroxyl group $\left(\mathrm{O}_{9} \mathrm{H}_{1}\right)$, a water molecule $\left(\mathrm{W}_{10}\right)$ which completes an $\mathrm{AlO}_{6}$ octahedron, a second water molecule $\left(\mathrm{W}_{11}\right)$ and a charge compensating $\mathrm{NH}_{4}{ }^{+}$cation (Fig. 3 and 4).

The diffracted intensities measured with an Enraf-Nonius CCD diffractometer to a resolution of $0.9 \AA^{-1}$ were fitted to the multipolar model [8, Eq. (2)] to a $R$ factor of $0.0102\left(R_{w}=0.0066, N_{\text {obs }}=4725\right)$.

Figure 5 gives the deformation density in an $\mathrm{Al}-\mathrm{O}-\mathrm{P}$ plane: the charge density accumulation close to the $\mathrm{O}$ atom in the $\mathrm{Al}-\mathrm{O}$ bond confirms that this bond has more ionic character than the $\mathrm{P}-\mathrm{O}$ bond. The hydrogen bond interaction between the $W_{11}$ water molecule and $\mathrm{O}_{4}$ clearly shows up on Fig. 5b. Also interesting is the banana shape of the deformation density of the bridging oxygen atom for $\mathrm{Al}-\mathrm{O}-\mathrm{Al}$ interactions when the $\mathrm{Al}-\mathrm{O}-\mathrm{Al}$ angle is close to $90^{\circ}$ as evidenced from Fig. 6 .

The $\mathrm{P}-\mathrm{O}$ Bond Critical Points (BCP) lie at $0.90 \AA$ from the oxygen atom and the charge density at $\mathrm{BCP}$ is related to the bond length, the longer the bond $(1.51 \rightarrow$ $1.55 \AA)$, the smaller the density $\left(1.67 \rightarrow 1.55 \mathrm{e}^{-3}\right)$. A similar behaviour is found for all $\mathrm{Al}-\mathrm{O}$ bonds $(1.83 \rightarrow$ $2.15 \AA$ ) whose density at the BCP decreases almost exponentially $\left(0.25 \rightarrow 0.56 \mathrm{e}^{-3}\right)$. The average topological charges and atomic volumes of the $\mathrm{P}, \mathrm{Al}$ and oxygen atomic basins of the framework are given in Table 1. For the sake of comparison, the kappa charges are also given.
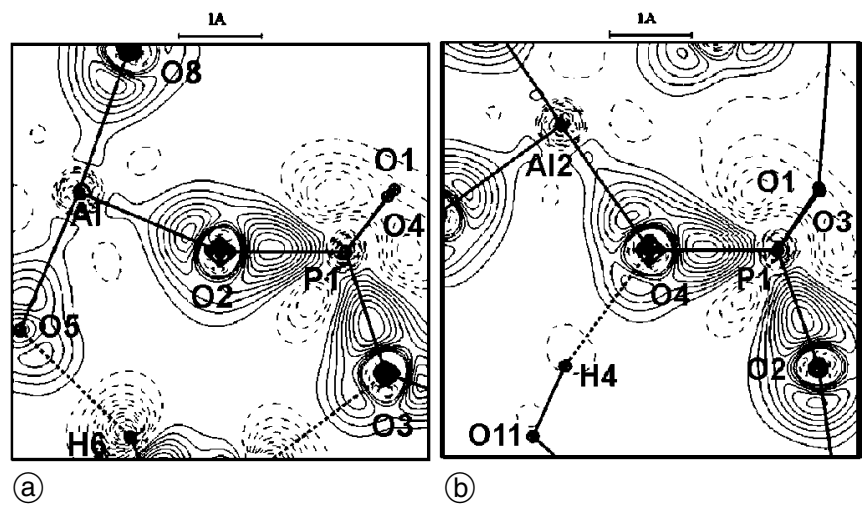

(a)

(b)

Fig. 5. Static electron density deformation maps (a) Al2-O2-P1 plane. (b) Al2-O4-P1 plane. The contour interval is 0.05 e $\AA^{-3}$; positive contours are shown as solid lines, negative contours are shown as dashed lines and zero contours have been omitted.

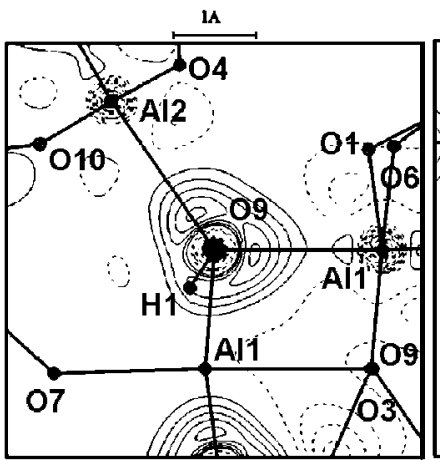

(a)

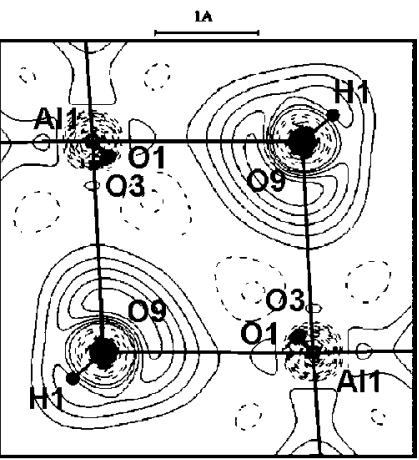

(b)
Fig. 6. Static electron density deformation maps (a) Al2-O9-Al1 plane. (b) Al1-O9-A11 plane. Contours as in Fig. 5.

The topological charges are closer to the formal oxidation numbers. A closer examination (Fig. 6) of the $\mathrm{O}$ and $\mathrm{P}$ topological charges shows that they are correlated to the $\mathrm{P}-\mathrm{O}$ bond lengths, the shorter the bond, the larger the charge.

A correlation was also found with the $\mathrm{Al}-\mathrm{O}-\mathrm{P}$ angles: the larger the angle, the more negative the oxygen atoms. Similar observations using theoretical calculations were made by Larin and Vercauteren for all siliceous and aluminophosphate molecular sieves [37, 38].

Electrostatic interaction energies of the two water molecules $\left(W_{10}\right.$ and $\left.W_{11}\right)$ occluded in $\mathrm{AlPO}_{4}-15$ were also estimated [26, 34]: $W_{10}$ is coordinated to an aluminium atom $(\mathrm{Al}-\mathrm{W}=1.94 \AA)$ whereas $W_{11}$ is a guest molecule hydrogen bonded to the framework via two $\mathrm{H}$ bonds to the $\mathrm{OH}^{-}$hydroxyl $(\mathrm{O} \cdots \mathrm{O}=3.019 \AA)$ and to the $W_{10}$ $(\mathrm{O} \ldots \mathrm{O}=2.701 \AA$ ) water molecule (Fig. 4). The electrostatic energy $E_{\mathrm{A} / \mathrm{B}}$ (energy of the $\mathrm{A}$ guest molecule occluded in the B framework) was evaluated numerically, using the experimental charge density and electrostatic potential.

$$
E_{\mathrm{A} / \mathrm{B}}=E_{\mathrm{A} / \mathrm{B}}^{e}+E_{\mathrm{A} / \mathrm{B}}^{n}
$$

with

$$
E_{\mathrm{A} / \mathrm{B}}^{n}=\sum_{j=1}^{N} Z_{j} \delta\left(\boldsymbol{r}-\boldsymbol{R}_{j}\right) V_{B}(\boldsymbol{r})
$$

and

$$
E_{\mathrm{A} / \mathrm{B}}^{e}=p^{3} \sum_{i j k} \varrho_{\mathrm{A}}^{e}(i, j, k) V_{\mathrm{B}}(i, j, k)
$$

where $p$ is the size of a $(i, j, k)$ pixel $(0.015 \AA)$ in a $5 \AA^{3}$ cubic box around the A guest molecule.

$V_{\mathrm{B}}$ is calculated as:

$$
V_{\mathrm{B}}(\boldsymbol{r})=V(\boldsymbol{r})-V_{\mathrm{A}}(\boldsymbol{r})
$$

Table 1. Mean topological charges and volumes $\left(\AA^{3}\right)$ for $\mathrm{AlPO}_{4}-15$.

\begin{tabular}{llll}
\hline & $\mathrm{P}$ & $\mathrm{Al}$ & $\mathrm{O}$ \\
\hline $\begin{array}{c}\text { Topological } \\
\text { charge }(\mathrm{e})\end{array}$ & $+3.465 \pm 0.015$ & $+2.425 \pm 0.005$ & $-1.49 \pm 0.06$ \\
$\begin{array}{c}\text { Topological } \\
\text { volume }\left(\AA^{3}\right)\end{array}$ & $3.13 \pm 0.03$ & $3.53 \pm 0.02$ & $14.8 \pm 0.7$ \\
Kappa charge (e) & $+1.30 \pm 0.01$ & $+1.60 \pm 0.02$ & $-0.87 \pm 0.06$ \\
\hline
\end{tabular}




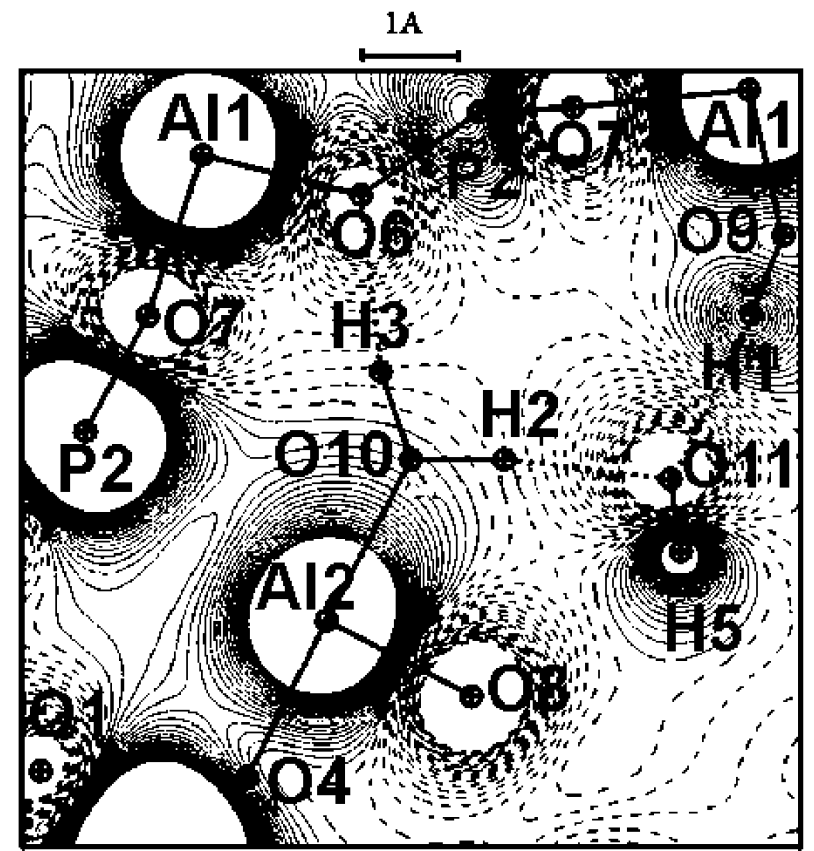

Fig. 7. Electrostatic potential $V_{\mathrm{B}}=V_{\text {Total }}-V_{\mathrm{A}}$ felt by the water molecule $\mathrm{A}\left(\mathrm{W}_{10}\right)$ linked to $\mathrm{Al}_{2}$ atom. $\mathrm{W}_{10}\left(\mathrm{O}_{10} \mathrm{H}_{2} \mathrm{H}_{3}\right)$ is represented at its position in the crystal.

where $V(\boldsymbol{r})$ is the total potential calculated according to (16), (17) and (18). This method is very close to that proposed for theoretical calculations by Gavezotti [25].

Figure 7 shows the electrostatic potential $V_{\mathrm{B}}$ at the $W_{10}$ water molecule site: the electric field (in the direction of the gradient of $V_{\mathrm{B}}$ ) is parallel to the dipole moment of the water molecule as expected to minimize the dipolar interaction. The negative $\mathrm{O}_{10}$ atom is in a region of positive potential whereas the positive $\mathrm{H}_{2}$ and $\mathrm{H}_{3}$ atoms sit in negative potential areas. Table 2 gives the integrated electronic, nuclear and total electrostatic interaction energies calculated with a null and $0.64 \mathrm{e}^{-1}$ inner potentials $\left(V_{0}\right.$ in Eq. (16)) for $\mathrm{W}_{11}, \mathrm{~W}_{10}$, compared to those of the hydroxyl and $\mathrm{NH}_{4}{ }^{+}$ions: all four entities have negative electrostatic

Table 2. Integrated number of electrons and electrostatic energy $(\mathrm{kJ} /$ mol) (electrons, nuclei and total) of $\mathrm{OH}, \mathrm{NH}_{4}^{+}, \mathrm{W}_{10}$ and $\mathrm{W}_{11}$ species occluded in $\mathrm{AlPO}_{4}-15$. The electrostatic energy is calculated according to Eq. (22-24), assuming a partition into A/B entities based upon atomic multipoles.

\begin{tabular}{lllll}
\hline & $\mathrm{O} 9 \mathrm{H} 1$ & $\mathrm{NH}_{4}^{+}$ & $w 10$ & $w 11$ \\
\hline $\begin{array}{c}\text { Expected number } \\
\text { of electrons }\end{array}$ & 9.30 & 10.22 & 9.86 & 9.83 \\
$\begin{array}{c}\text { Integrated number } \\
\text { of electrons }\end{array}$ & 9.33 & 10.23 & 9.90 & 9.86 \\
\hline
\end{tabular}

Electrostatic interaction energies

$\begin{array}{lrrrr}\text { Electronic part } E_{\mathrm{A} / \mathrm{B}}^{\mathrm{e}} & -9040 & +4610 & -2610 & -1920 \\ \text { Nuclear part } E_{\mathrm{A} / \mathrm{B}} & +7430 & -5350 & +1950 & +1430 \\ \text { Total }\left(V_{0}=0.64 \mathrm{e} \AA^{-1}\right)^{b} & -1610 & -740 & -670 & -490 \\ \text { Total }\left(V_{0}=0.00 \mathrm{e} \AA^{-1}\right)^{b} & -1350 & -1430 & -790 & -640\end{array}$

a: Calculated from the $P_{\text {val }}$ population coefficient of the multipolar model (Eq. 2).

b: $V_{0}$ is the mean inner potential. energies; they are therefore stabilized inside the $\mathrm{AlPO}_{4}-15$ framework.

Moreover, the two water molecules are predicted to be less stable than the $\mathrm{OH}^{-}$and $\mathrm{NH}_{4}{ }^{+}$cations as observed from a thermogravimetric experiment [39]. One also can see that the $\mathrm{W}_{10}$ structural water molecule is the second species to leave the structure. The strong electrostatic stabilization energies (Table 2) are also in line with the rather high desorption temperatures (resp. 173 and $233{ }^{\circ} \mathrm{C}$ ).

In conclusion, this study shows that high resolution $\mathrm{X}$ ray diffraction provides fundamental energetic quantities and an accurate crystal structure; it allows experimental modelling of host-guest interactions. Furthermore, these model studies lead to interesting correlations between topological and stereochemical information that is being used in our laboratory to build a data bank of electrostatic parameters; the aim of this bank is to describe new porous materials for which such accurate crystallography is not feasible due, for example, to their poor crystallinity.

\section{Magnetic molecular compounds}

Another interesting application of accurate crystallography is Molecular Magnetism: molecular-based magnetic materials have been the subject of intense investigations over the last decade mainly due to their potential applications in information storage devices [40]: hence new physical properties like photo induced magnetization, single molecule quantum behaviour, molecular bistability have been recently described [41].

Such materials are based on molecular magnetic building blocks connected via covalent, coordination interactions or intermolecular $\mathrm{H}$ bonds. The resultant magnetic properties at the macroscopic scale depend on the nature and strength of those interactions. Despite their potentiality, surprisingly only few X-ray high resolution studies have been devoted to these materials [see for example 15, 42-48]. Among the work performed in our laboratory in this field, we will describe two coordination compounds:

- $\mathrm{MnCu}(\mathrm{pba}) \quad\left(\mathrm{H}_{2} \mathrm{O}\right)_{3} \cdot 2 \mathrm{H}_{2} \mathrm{O}$ [44] a ferrimagnetic chain compound,

- $\left[\mathrm{Fe}(\mathrm{btr})_{2}(\mathrm{NCS})_{2}\right] \mathrm{H}_{2} \mathrm{O}$ a molecule which undergoes thermally and photoinduced spin-state transitions [56].

\section{Charge density study of $\mathrm{MnCu}(\mathrm{pba})\left(\mathrm{H}_{2} \mathrm{O}\right)_{3} \cdot 2 \mathrm{H}_{2} \mathrm{O}$ [44]}

Figure 8 shows the chain structure of this ferrimagnetic compound ( $\mathrm{pba}=1,3$-propylene bis (oxamato)). The copper atom has pyramidal coordination whereas $\mathrm{Mn}$ is octahedrally coordinated.

This compound exhibits one dimensional antiferromagnetic interactions and weak inter-chain couplings as shown from magnetic measurements and polarized neutron diffraction experiments $[49,50]$. Negative and positive spin populations found on $\mathrm{Cu}\left(-0.75 \mu_{\mathrm{B}}\right)$ and $\mathrm{Mn}\left(+4.93 \mu_{\mathrm{B}}\right)$ demonstrate antiferromagnetic interactions. Spin densities have also been observed on the oxamato ligand, resulting from spin delocalization. Figure 9 shows the total charge 


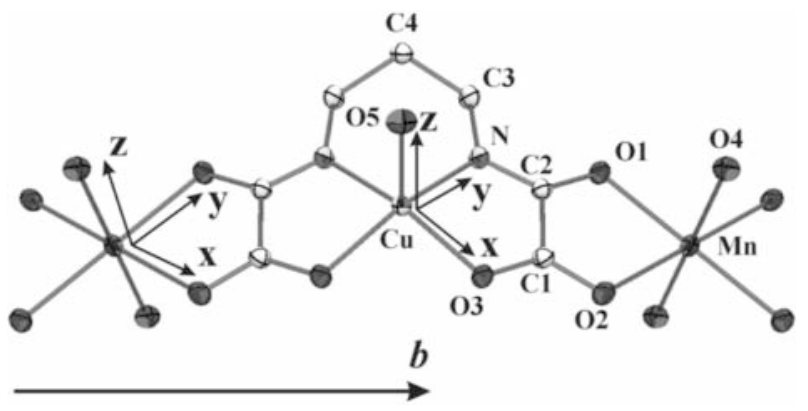

Fig. 8. Ortep drawing of the chain structure of $\mathrm{MnCu}(\mathrm{pba})\left(\mathrm{H}_{2} \mathrm{O}\right)_{3} \cdot 2 \mathrm{H}_{2} \mathrm{O}$.

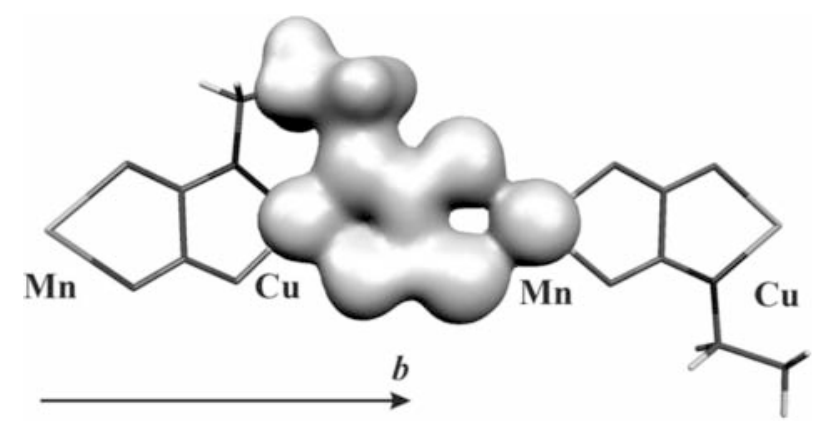

Fig. 9. Total electron density along the bimetallic chain of $\mathrm{MnCu}(\mathrm{pba})\left(\mathrm{H}_{2} \mathrm{O}\right)_{3} \cdot 2 \mathrm{H}_{2} \mathrm{O}$. (isosurface of $0.25 \mathrm{e}^{-3}$ ).

Table 3. Topological properties of the metal ligand bond critical points.

\begin{tabular}{lllll}
\hline $\begin{array}{l}\text { Bond } \\
(x-y)\end{array}$ & $\begin{array}{l}d(x-y) \\
\AA\end{array}$ & $\begin{array}{l}d(x-\mathrm{CP}) \\
\AA\end{array}$ & $\begin{array}{l}d(y-\mathrm{CP}) \\
\AA\end{array}$ & $\begin{array}{l}\varrho_{\mathrm{cp}} \\
\mathrm{e} \AA^{-3}\end{array}$ \\
\hline $\mathrm{Cu}-\mathrm{O}_{3}$ (oxamato) & $1.996(1)$ & 0.92 & 1.08 & 0.62 \\
$\mathrm{Cu}-\mathrm{N}$ & $1.948(1)$ & 0.91 & 1.04 & 0.74 \\
$\mathrm{Cu}-\mathrm{O}_{5}\left(\mathrm{H}_{2} \mathrm{O}\right)$ & $2.271(1)$ & 1.10 & 1.17 & 0.32 \\
$\mathrm{Mn}-\mathrm{O}_{1}$ (oxamato) & $2.160(1)$ & 1.08 & 1.08 & 0.34 \\
$\mathrm{Mn}-\mathrm{O}_{2}$ (oxamato) & $2.172(1)$ & 1.05 & 1.12 & 0.40 \\
$\mathrm{Mn}-\mathrm{O}_{4}\left(\mathrm{H}_{2} \mathrm{O}\right)$ & $2.201(1)$ & 1.06 & 1.14 & 0.37 \\
\hline
\end{tabular}

Table 4. Atomic and fragment topological charges (e) and volumes $\left(\AA^{3}\right)$. The total charge and integrated volume summed over the unit cell are -0.07 e and $176.7 \AA^{3}$ respectively, which represent total errors of 0.07 e and $0.07 \%$ respectively due to the integration procedure.

\begin{tabular}{llllllll}
\hline & $\mathrm{Cu}$ & $\mathrm{Mn}$ & $\mathrm{O} 1$ & $\mathrm{O} 2$ & $\mathrm{O} 3$ & $\mathrm{~N}$ & $\mathrm{C} 1$ \\
\hline Charge & +1.56 & +1.45 & -0.97 & -0.87 & -0.80 & -1.15 & +1.38 \\
Volume & 9.46 & 10.80 & 13.72 & 16.44 & 14.39 & 13.89 & 4.90 \\
& $\mathrm{C} 2$ & $\mathrm{C} 3$ & $\mathrm{C}^{2} \mathrm{H}_{2}$ & $\mathrm{C} 4$ & $\mathrm{C}_{4} \mathrm{H}_{2}$ & $\begin{array}{l}\text { Oxamato } \\
\text { group }\end{array}$ & \\
& & & & & & & \\
Charge & +0.87 & -0.20 & +0.30 & -0.78 & -0.16 & -1.54 & \\
Volume & 7.34 & 11.35 & 23.24 & 11.74 & 19.70 & 70.68 & \\
& $\mathrm{O} 4$ & $\mathrm{H}_{2} \mathrm{O} 4$ & $\mathrm{O} 5$ & $\mathrm{H}_{2} \mathrm{O} 5$ & $\mathrm{O} 6$ & $\mathrm{H}_{2} \mathrm{O} 6$ & \\
Charge & -1.65 & -0.34 & -1.32 & 0.06 & -1.35 & 0.04 & \\
Volume & 22.28 & 25.58 & 20.02 & 23.70 & 21.86 & 25.32 & \\
\hline
\end{tabular}

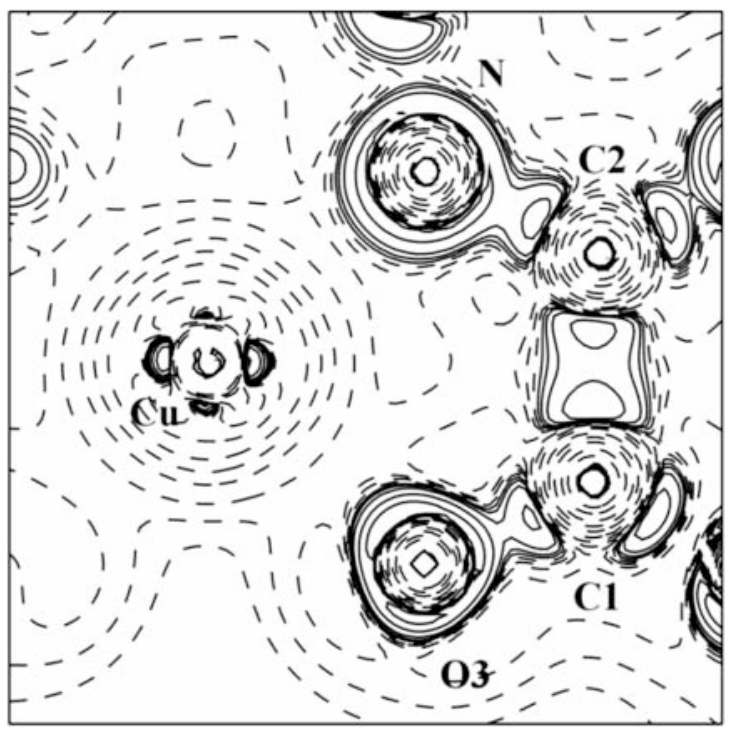

Fig. 10. Contour map of the Laplacian of the electron density in the $\mathrm{Cu}-\mathrm{O} 3-\mathrm{N}$ plane of $\mathrm{MnCu}(\mathrm{pba})\left(\mathrm{H}_{2} \mathrm{O}\right)_{3} \cdot 2 \mathrm{H}_{2} \mathrm{O}$.

density along the bimetallic chain: the orbital overlap is higher on the copper side of the oxamato bridge than on the manganese side as also revealed by the electron density at the corresponding metal-ligand bond critical points (Table 3); the charge accumulation is higher at the $\mathrm{Cu}-\mathrm{N}$ $\mathrm{BCP}$, which reveals a larger metal-ligand overlap than at the $\mathrm{Cu}-\mathrm{O}$ bond critical point.

Table 4 gives the topological charges and volumes of atoms and molecular fragments: both metals $\left(q_{\mathrm{Cu}}=1.56 \mathrm{e}\right.$, $\left.q_{\mathrm{Mn}}=1.5 \mathrm{e}\right)$ transfer electrons to the oxamato group $\left(q_{\text {oxamato }}=-1.54 \mathrm{e}\right)$, which appears highly polarized with positive $\mathrm{C}$ inner carbons and negative $\mathrm{O}$ and $\mathrm{N}$ coordinating atoms ( -0.88 and -1.15 respectively). The $\mathrm{Cu} 3 \mathrm{~d}$ orbital populations, as calculated according to [51], are 24.5, 11.0 and $16.5 \%$-for the $(\mathrm{d} x y, \mathrm{~d} y z, \mathrm{~d} x z), \mathrm{d} x^{2}-y^{2}$ and $\mathrm{d} z^{2}$ orbitals respectively (see Fig. 8 for reference axis) whereas the Mn populations are more isotropic. The Laplacian map confirms this result with accumulation in the populated orbitals (Fig. 10). This finding supports the polarized neutron results [49]: the less populated $\mathrm{d} x^{2}-y^{2}$ accepts one single electron in agreement with the significant spin density refined on this orbital.

\section{Thermally and photoinduced spin transitions}

\section{Thermal transition}

Transition metal ions from $\mathrm{d}^{4}$ to $\mathrm{d}^{7}$ in an octahedral environment may exhibit different spin states (high spin (HS), low spin (LS)) depending on the crystal field which evolves with external parameters $(T, P, \mathrm{~h} v)$. If this crystal field effect is of the order of the electron pairing energy, a spin conversion (or transition) may occur [52-56] upon application of variation of external conditions; such compounds are called spin crossover complexes. $\left[\mathrm{Fe}(\mathrm{btr})_{2}(\mathrm{NCS})_{2}\right] \cdot \mathrm{H}_{2} \mathrm{O}$ is the archetype of highly cooperative spin crossover complexes, resulting from a 2D crystal structure and characterized by abrupt thermal transitions (123.5 K and $144.5 \mathrm{~K}$ in the cooling (HS $\rightarrow$ LS) and warming mode (LS $\rightarrow$ HS) respectively) with a $21 \mathrm{~K}$ hysteresis and by a photoinduced transition at $T<$ 


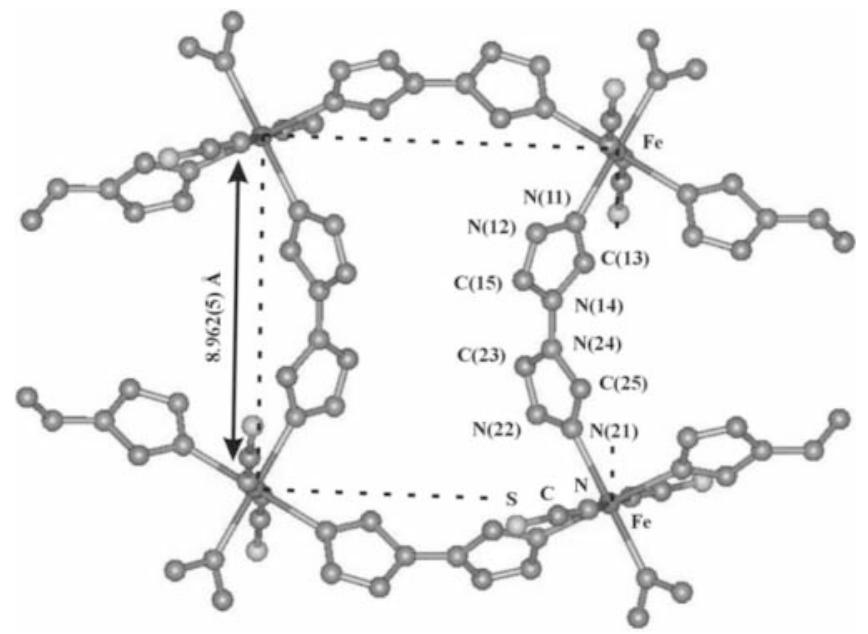

Fig. 11. Layer structure of $\left[\mathrm{Fe}(\mathrm{btr})_{2}(\mathrm{NCS})_{2}\right]\left(\mathrm{H}_{2} \mathrm{O}\right)$ in the HS state.

$60 \mathrm{~K}$. The low temperature LS molecules are promoted to a long living metastable HS state by photoexcitation: LIESST effect (Light Induced Excited Spin State Trapping). This type of material is very promising for its possible use in switching or memory devices as soon as the photocontrol of the associated properties is better understood. Following these lines, a full crystallographic study of $\mathrm{Fe}(\text { btr })_{2}(\mathrm{NCS})_{2} \cdot \mathrm{H}_{2} \mathrm{O}$ was undertaken to accurately describe the structural and electronic modifications occurring during temperature change [56] and photoexcitation [57]. Figure 11 shows the room temperature (RT) high spin structure and illustrates the 2D character of the crystal packing ( $\boldsymbol{b}, \boldsymbol{c}$ plane, $C 2 / c$ space group). The iron atom lies at the centre of a distorted $\mathrm{FeN}_{6}$ octahedron, with the two NCS anions in trans position.

The thermal behaviour of the complex was followed from RT to $104 \mathrm{~K}$, and then back to RT with measurements of cell parameters every $10 \mathrm{~K}$; the LS crystal structure has been refined from the $104 \mathrm{~K}$ data. Figure 12 shows the variation of the cell parameters when the structure undergoes the HS $\rightarrow$ LS thermal hysteresis and the photoinduced LS $\rightarrow$ HS transitions $(T<60 \mathrm{~K})$.

On going from HS to LS state (at $123.5 \mathrm{~K}$ ), $\boldsymbol{b}$ and $\boldsymbol{c}$ parameters decrease when $\boldsymbol{a}$ increases. This is in line with

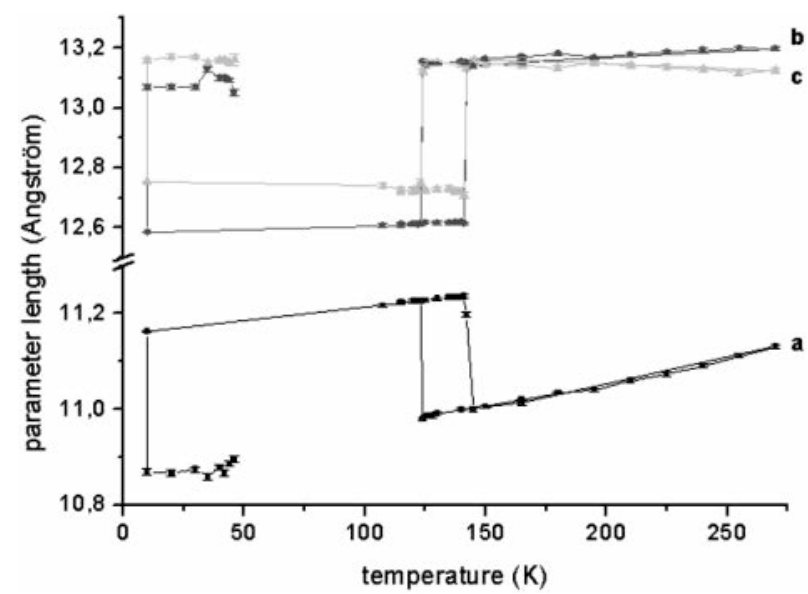

Fig. 12. Evolution of unit cell parameters between $270 \mathrm{~K}$ et $10 \mathrm{~K}$. The HS metastable state was obtained at $10 \mathrm{~K}$ by laser irradiation (Argon-Krypton $\lambda=488 \mathrm{~nm} ; 40 \mathrm{~mW}$ ).

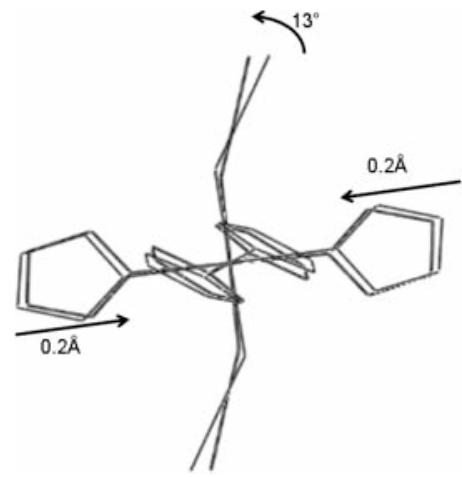

Fig. 13. Superposition of the RT HS (blue) and $104 \mathrm{~K} \mathrm{LS}$ (purple) structures.

the crystal structure modification (Fig. 13), the F-N (btr) bonds are directed parallel to the $(\boldsymbol{b}, \boldsymbol{c})$ plane and decrease by $\sim 0.2 \AA$ whereas the $\mathrm{Fe}-\mathrm{NCS}$ angle increases from 153 to $163^{\circ}$ (in the $\boldsymbol{a}$ direction). Such a structural effect was already extensively described by Marchivie et al. ([58] and references therein).

Single crystal dynamic measurements (Fig. 14) of the spin conversion at $117.2 \mathrm{~K}$ demonstrates the spin-like domain structure of the material when the transition $\mathrm{HS} \rightarrow$ LS occurs: at intermediate times, both spin states coexist, in the crystal, in well-defined domains, as revealed by distinct HS and LS Bragg spots. A precise evolution of the HS to LS species is described in details in [56]; in particular, the HS and LS states are evidenced from difference Fourier maps where the anisotropy of $d$ electrons clearly shows up in the LS state (Fig. 7 in Ref. [56]).

\section{Photoinduced spin transition}

Photoexcitation of $\mathrm{Fe}(\mathrm{btr})_{2}(\mathrm{NCS})_{2} \cdot \mathrm{H}_{2} \mathrm{O}$ was achieved on a single crystal mounted on an Oxford Diffraction diffractometer equipped with an Helijet gas stream and irradiated with an argon-krypton laser $(\lambda=488 \mathrm{~nm}, 40 \mathrm{~mW}, 10 \mathrm{~K})$. Figure 15 shows the dynamic behaviour of the transition: at $t=0 \mathrm{mn}$, the observed (026) Bragg peak corresponds to the LS structure; at $t=4 \mathrm{mn}$, both HS and LS states are clearly identified and the transition to a pure HS spin state is complete after 15 minutes [57]. The structure of this HS metastable state has been refined (10 K data) and is similar to that obtained at room temperature (Fig. 11). The accurate structure and electron density analysis are

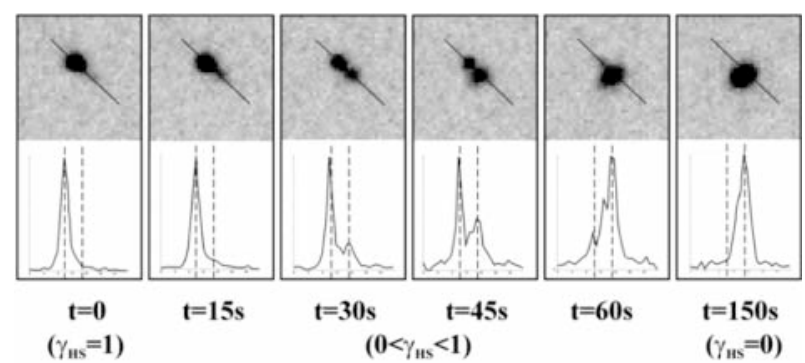

Fig. 14. Dynamic of the spin conversion for a $\left[\mathrm{Fe}(\mathrm{btr})_{2}(\mathrm{NCS})_{2}\right]\left(\mathrm{H}_{2} \mathrm{O}\right)$ single crystal whose spin transition was observed at $T=117.2 \mathrm{~K}$. Each picture corresponds to the instantaneous (at $t=0,15,30,45$, $60,150 \mathrm{~s}) 2 \mathrm{D}$ diffraction profile of the (206) reflection (upper part) and intensity line profile (lower part) along the radial $\theta$ direction. Intensity profiles are given with arbitrary units. 


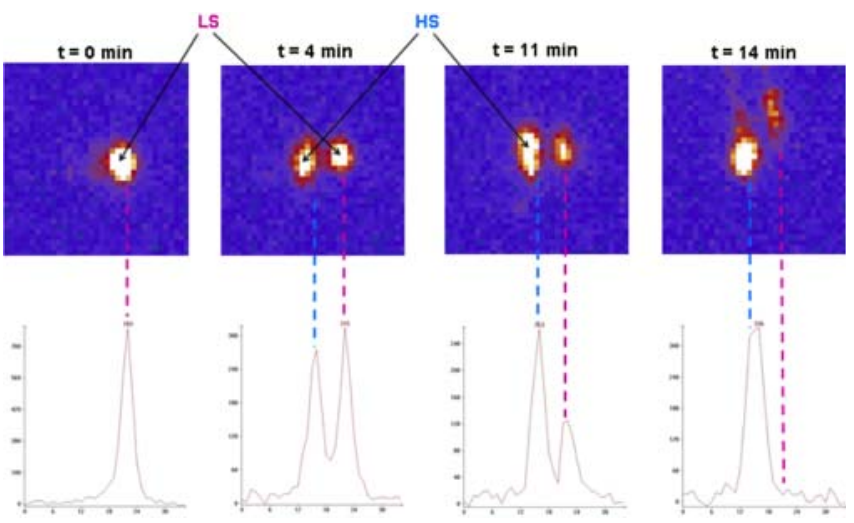

Fig. 15. Kinetic of the photoinduced LS to HS conversion of $\left[\mathrm{Fe}(\mathrm{btr})_{2}(\mathrm{NCS})_{2}\right] \cdot \mathrm{H}_{2} \mathrm{O}(\lambda=488 \mathrm{~nm} ; 10 \mathrm{~K} ; 40 \mathrm{~mW})$. Evolution of the 2D diffraction profile of the (026) reflection versus time.

still under development and will be published in a forthcoming paper. The preliminary results confirm the spin state of the molecular complex.

\section{Frontier applications in life sciences}

The first applications given above show that experimental electron density studies bring new insights in various areas of small molecule and material science crystallography. This last part intends to show that this approach can now be extended to macromolecular systems; such an extension allows electrostatic energy calculations to understand and to score interactions between proteins active site and their cofactor, ligand or inhibitor [59-62]. In parallel to the experimental development of the X-ray methodology [8], it is interesting to note that recent theoretical methods in Density Functional Theory (DFT) like linear scaling (which scales linearly with the number of atoms instead of the cube [63]) allows first principles quantum calculations on polypeptide and protein systems [64]. Both experimental and theoretical results have therefore to be compared to jointly improve them. This latter approach was very successful for small molecules crystallography (see for example [16-18]).

Since 1990, the number of high and ultra-high resolution protein X-ray diffraction data has increased almost exponentially [65-67]. Some of these data sets are accurate enough to deserve a multipolar refinement [61-63, 68, 69]: they permit a more accurate location of most hydrogen atoms of the active site and reveal the bonding density. The probability of observing these features depends on the resolution, which is directly related to the thermal displacement parameters as shown on Fig. 16.

High resolution X-ray diffraction studies have been performed in Nancy on a large group of mono-, di- or tripeptides in order to precisely determine the electron density distribution of all natural amino-acids. These studies allowed building an experimental data base of atomic charge density parameters $\left(P_{\text {val }}, P_{l m}, \kappa, \kappa^{\prime}\right)$ [70] for each type of atom in a given chemical environment. These parameters were shown to be transferable to amino acids in proteins [70].

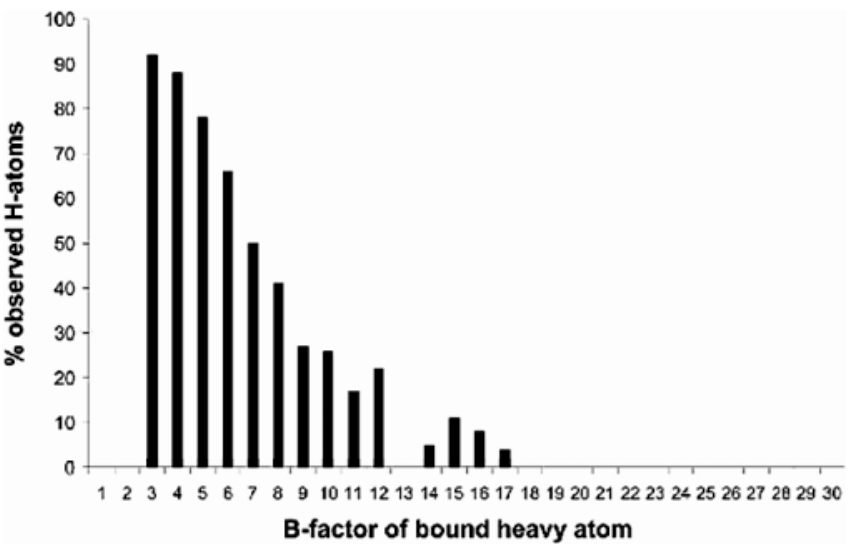

Fig. 16. Percentage of the hydrogen atoms observed (according to the equivalent $\mathrm{B}$ temperature factor of the heavy atoms to which $\mathrm{H}$ atoms are bonded) in the structure of aldose reductase, refined at $0.66 \AA$ resolution.

More recently, Coppens et al. have proposed a similar data base computed from DFT calculations [71]. A comparison between these data bases is given in Ref. [72]. Such data bases are the starting point for multipolar refinement: the experimental data base has been tested on the protein crambin which is a small 46 residues protein; Xray data have been measured on BW7A line of DORIS (Hamburg) synchrotron to a resolution of $d=0.54 \AA$ by Teeter et al., which is still the world record for a protein [62]. The average dynamic deformation map (Fig. 17) over the 34 non-disordered peptides residues displays significant residual density in the bonds between non hydrogen atoms and on oxygen lone pairs at their expected positions. These features demonstrate that these data deserve a multipolar model [13].

At the end of the refinement, the static deformation electron density of the average peptide residue is in almost quantitative agreement with that derived from a triple zeta HF calculation on a single monopeptide [16].

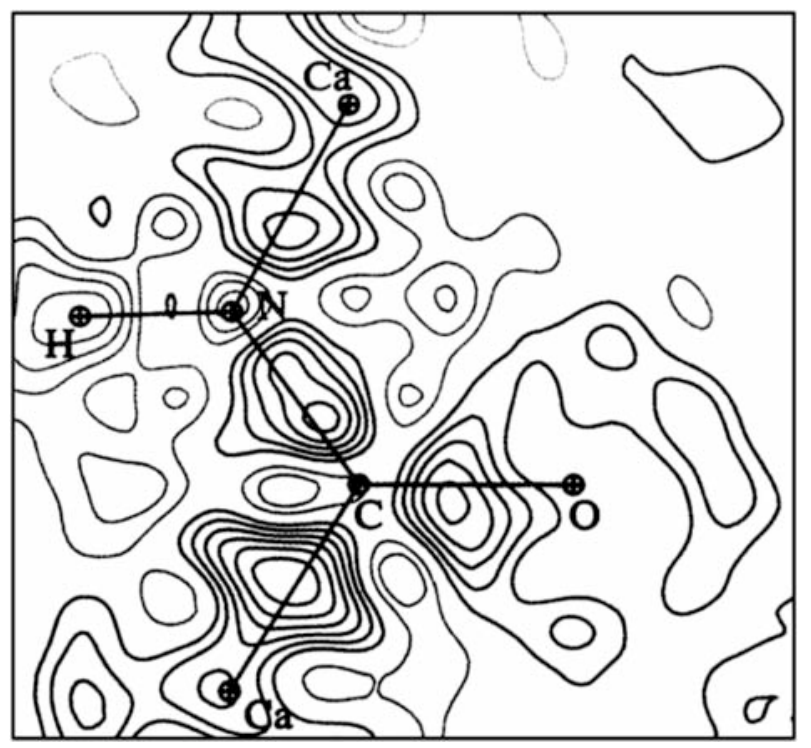

Fig. 17. Residual electron density averaged over the 34 non disordered peptide groups of crambin after an IAM modelling. Positive density in black and negative in grey contours of $0.1 \mathrm{e}^{-3}$. 


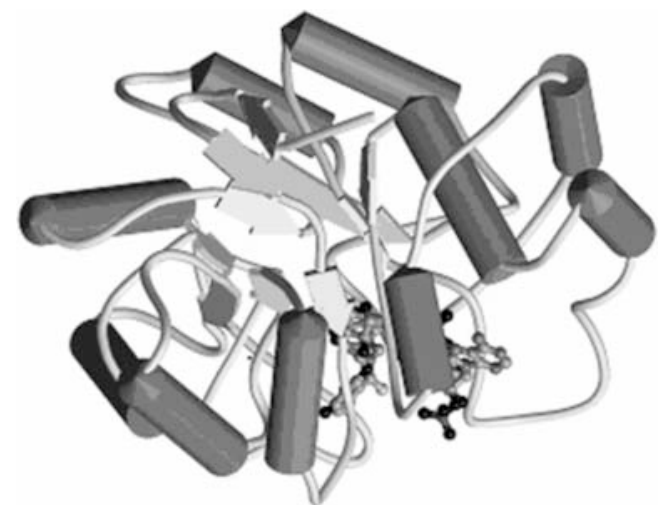

Fig. 18. Schematic view of the Human Aldose Reductase structure, with alpha helixes represented as tubes, beta strands as arrows and loops as coils. The $\mathrm{NADP}^{+}$cofactor and the inhibitor are showed in ball and stick mode, indicating the position of the active site.

As these results were encouraging, a new refinement program was written to combine the advantages of small molecules and proteins refinement (MoPro: http:// www.lcm3b.uhp-nancy.fr, [8]). An example of the refinement strategy applied to the aldose reductase protein (Fig. 18) is given in [73]: the aldose reductase data have been collected to $0.66 \AA$ resolution [68, 69, 74]. Figure 19 gives the static deformation density obtained from the constrained multipolar refinement. The quality of the map allowed electrostatic potential calculations: it was the first experimental evidence of the electrostatic complementarity between the active site, the ligand and the protein's inhibitor [59, 75].

Other applications have been performed on Scorpio Toxin [61], Tripsin [62].

\section{Conclusion}

These few examples of high resolution crystallography show that charge density research is being applied to a broad variety of research projects and gives answers that

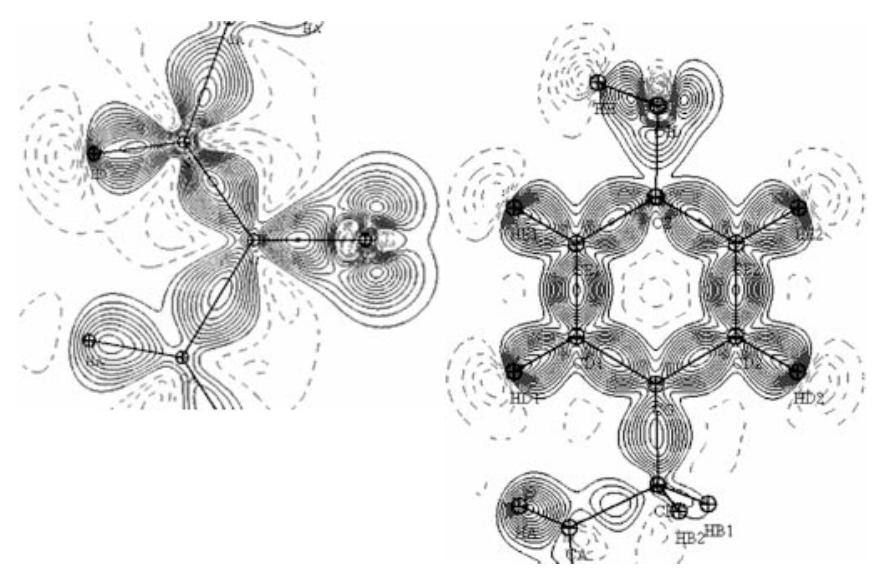

(a)

(b)

Fig. 19. Static deformation densities after a constrained multipolar refinement. (a) in the protein peptide plane. (b) in the $\mathrm{C}_{6}$ plane of a tyrosine residue. Contours are $0.05 \mathrm{e}^{-3}$, positive in full and negative in broken lines. are not attainable by other experimental techniques. The future of these methods parallels the development of new X-ray sources which will enable crystallographers to perform time resolved experiments at times smaller than picosecond [76-77].

Acknowledgments. Prof. N. E. Ghermani and Dr. M. Souhassou are gratefully acknowledged. This work was funded by CNRS (SPM) and University Henri Poincaré - Nancy I.

\section{References}

[1] Lecomte, C.: Preface in the Rigaku Journal 19 (2002) 1-3.

[2] Rousse, A.; Aubebert, P.; Gendre, J. P.; Fallies, F.; Gauthier, J. C.; Mysyrowicz, A., Grillon, G.; Antonetti, A.: Efficient $K_{\alpha}$ X-ray source from femtosecond laser-produced plamas. Phys. Rev. E. 50 (1994) 2200-2207.

[3] Coppens, P.: X-ray charge densities and chemical bonding (1997) Oxford University Press, N.Y., 1997.

[4] Coppens, P.: What can time-resolved diffraction tell us about transcient species?: excited-state structure determination at atomic resolution. Chem. Comm. (2003) focus article, 1317-1320.

[5] Kim, C. D.; Pillet, S.; Guang, Wu G.; Fullagar, W. K.; Coppens, P.: Excited state structure by time-resolved X-ray diffraction. Acta Cryst. A58 (2002) 153-157.

[6] Kuntzinger, S.; Dahaoui, S.; Ghermani, N. E.; Lecomte, C.; Howard, J. A. K.: The use of CCD area detectors in charge density research. Application to a mineral compound: the $\alpha$-spodumene $\mathrm{LiA}\left(\mathrm{SiO}_{3}\right)_{2}$. Acta Cryst. B55 (1999) 867-881.

[7] Koritsanszky, T.; Howard, S. T.; Richter, T.; Mallinson, P. R.; $\mathrm{Su}$, Z.; Hansen, N. K.: XD A computer program package for multipole refinement and analysis of charge densities from $\mathrm{X}$ ray diffraction data. Free University Berlin, Germany.

[8] Guillot, B.; Viry, L.; Guillot, R.; Lecomte, C.; Jelsch C.: Refinement of proteins at subatomic resolution with MOPRO. J. Appl. Cryst. 34 (2001) 214-223.

[9] Blessing, R. H.; Lecomte, C.: The Application of Charge Density Research to Chemistry and Drug Design. (G. A. Jeffrey, J. F. Piniella, Eds.) NATO Advanced Studies Institute, B250, Plenum Press, New York (1991) 155-185.

[10] Sörensen, H. O.; Larsen, S.: Measurement of high quality diffraction data with a Nonius Kappa CCD diffractometer: finding the optimal experimental parameters. J. Appl. Cryst. 36 (2003) 931-939.

[11] Stewart, R. F.: Generalized X-ray scattering factors. J. Chem. Phys. 51 (1969) 4569-4577.

[12] Coppens, P.; Guru Row, T. N.; Leung, P.; Stevens, E. D.; Becker, P. J.; Yang, Y. W.: Net atomic charges and molecular dipole moments from spherical atom X-ray refinements, and the relation between atomic charge and shape. Acta Cryst. A35 (1979) 63-72.

[13] Hansen, N. K.; Coppens, P.: Testing aspherical refinement on small molecules data sets. Acta Cryst. A34 (1978) 909-921.

[14] Lecomte, C.: Electron density models: description, comparison and applications. In: The application of charge density research to chemistry and drug design. NATO Adv. Studies (G. A. Geffrey and J. F. Piniella, Eds.) (1991) 121-153.

[15] Claiser, N.; Souhassou, M.; Lecomte, C.; Pontillon, Y.; Romero, F.; Ziessel, R.: Understanding magnetic interaction pathways: an experimental determination of electron density in a alkyne-substituted nitronyl nitroxide radical. J. Phys. Chem. B 106 (2002) 12896-12907.

[16] Souhassou, M.; Lecomte, C.; Ghermani, N. E.; Rohmer, M. M.; Wiest, R.; Bénard, M.; Blessing, R. H.: Electron distribution in peptides and related molecules: an experimental and theoretical study of [Z]-N-acetyl $\alpha-\beta$ dehydrophenylalanine methylamide. J. Am. Chem. Soc. 114 (1992) 2371-2383.

[17] Pichon-Pesme, V.; Lecomte, C.; Wiest, R.; Bénard, M.: Modelling fragments for the ab initio determination of electron density in polypeptides: an experimental and theoretical approach to the electron density in leu-enkephalin, $3 \mathrm{H}_{2} \mathrm{O}$. J. Am. Chem. Soc. 114 (1992) 2713-2715.

[18] Pillet, S.; Souhassou, M.; Lecomte, C.; Schwarz, K.; Blaha, P.; Rerat, M.; Lichanot, A.; Roversi, P.: Recovering experimental 
and theoretical electron densities in corundum using the multipolar model: IUCr multipole project. Acta Cryst. A57 (2001) 290-303.

[19] Bader, R. F. W.: Atoms in molecules. A quantum theory (1990) Oxford University Press, Oxford, UK.

[20] Ghermani, N. E.; Lecomte, C.; Bouhmaida, N.: Electrostatic potential from high resolution X-ray diffraction: application to a pseudopeptide. Z. Naturforschung 48a (1993) 91-98.

[21] Stewart R. F.: On the mapping of electrostatic properties from Bragg diffraction data. Chem. Phys. Lett. 65 (1979) 335-342.

[22] Bouhmaida, N.; Ghermani, N. E.; Lecomte, C.; Thalal, A.: Molecular fragment electric moments derived from the fit of the experimental electrostatic potential. Application to water molecule. Acta Cryst. A55 (1999) 729-739.

[23] Volkov, A.; Li, X.; Koritsanszky, T.; Coppens, P.: Ab initio quality electrostatic atomic and molecular properties including intermolecular energies from a transferable theoretical pseudoatom databank. J. Phys. Chem. A108 (2004) 4283-4300.

[24] Spackman, M. A.; Weber, H. P.; Craven, B. M.: Energies of molecular interactions from Bragg diffraction data. J. Am. Chem. Soc. 110 (1998) 775-782.

[25] Gavezotti, A.: Calculation of intermolecular interaction energies by direct numerical integration over electron densities. J. Phys. Chem. B106 (2002) 4145-4154.

[26] Aubert, E.; Porcher, F.; Souhassou, M.; Lecomte, C.: Electrostatic potential and interaction energies of molecular entities occluded in the $\mathrm{AlPO}_{4}-15$ molecular sieve. J. Phys. Chem. Solids 65 (2004) 1943-1949.

[27] Shirsat, R. N.; Bapat, S. V.; Gadre, S. R.: Molecular electrostatics. A comprehensive topographical approach. Chem. Phys. Letters 200 (1992) 373-378.

[28] Gadre, S. R.; Kulkarni, S. A.; Suresh, C. H.; Shrivastava, I. H.: Basis set dependence of molecular electrostatic potential topography: A case study of substituted benzenes. Chem. Phys. Letters (1995) 239-273.

[29] Gadre, S. R; Pingale, S. S.: Polarization-corrected electrostatic potential for probing cation binding patterns of molecules. 1. Saturated hydrocarbons. J. Am. Chem. Soc. 120 (1998) 7056 -7062.

[30] Leboeuf, M.; Köster, A. M.; Jug, K.; Salahub, D. R.: Topological analysis of the molecular electrostatic potential. J. Chem. Phys. 111 (1999) 4893.

[31] Tsirelson, V. G.; Avilov, A.S.; Lepeshov, G. G.; Kulygin, A. K.; Stahn, J.; Pietsch, U.; Spence, J. C. H.: Quantitative analysis of the electrostatic potential in Rock-Salt crystals using accurate electron diffraction data. J. Phys. Chem. B105 (2001) 50685074.

[32] Bouhmaida, N.; Dutheil, M.; Ghermani, N. E.; Becker, P.: Gradient vector field and properties of the experimental electrostatic potential: application to Ibuprofen drug molecule. J. Chem. Phys. 116 (2002) 6196-6204.

[33] Politzer, P.; Grice, M. E.; Murray, J. S.: Electronegativities, electrostatic potentials and covalent radii. J. Mol. Struct. (Theochem) 549 (2001) 69-76.

[34] Porcher, F.; Aubert, E.; Souhassou, M.; Lecomte, C.: Estimating adsorption energy in AlPO4-15 molecular sieve - Some approaches based on experimental charge density modelling. $22^{\text {th }}$ European Crystallographic Meeting, Abstract book s54.

[35] Braun, I.; Iklein, G.; Laeri, F.; Nöckel, J. U.; Schulz-Ekloff, G.; Schüth, F.; Vietze, U.; Waß, O.; Wöhrle, D.: Hexagonal microlasers based on organic dyes in nanoporous crystals. Appl. Phys. B70 (2000) 335-343.

[36] Aubert, E.; Porcher, F.; Souhassou, M.; Lecomte, C.: Characterisation of intra framework and guest/host interactions in the $\mathrm{AlPO}_{4}-15$ molecular sieve: experimental versus procrystal charge density analysis. Acta Cryst. B59 (2003) 687-700.

[37] Larin, A. V.; Vercauteren, D. P.: Approximation of the Mulliken charges for the oxygen and silicon atoms of zeolite frameworks calculated with a periodic H. F scheme. Int. J. Quant. Chem. 70 (1998) 993-1001.

[38] Larin, A. V.; Vercauteren, D. P.: Approximation of the Mulliken charges and dipole moments of oxygen atoms of aluminophosphate sieves. J. Mol. Cat. A: Chemical 166 (2001) 73-85.

[39] Aubert, E.: PhD Thesis, Université Henri Poincaré, Nancy 1 (2003) Etude des interactions de molécules hôtes dans des zéo- lites synthétiques par diffraction des rayons $\mathrm{X}$ à haute résolution.

[40] Kahn, O.: Molecular magnetism. VCH (1993) New York.

[41] Miller, J.; Drillon, M.: Magnetism: molecules to materials I, II, III, IV, VCH (2001, 2002, 2003), New York.

[42] Figgis, B. N.; Kucharski, E. S.; Vrtis, M.: Spin and charge transfer through hydrogen bonding in $\left[\mathrm{Co}\left(\mathrm{NH}_{3}\right)_{5}\left(\mathrm{OH}_{2}\right)\right]$ $\left[\mathrm{Cr}(\mathrm{CN})_{6}\right]$. J. Am. Chem. Soc. 115 (1993) 176-181.

[43] Yasui, M.; Takayama, R.; Akiyama, N.; Hashizume, D.; Iwasaki, F.: Electron density distributions of pyrimidine-bridged $\mathrm{Cu}$, $\mathrm{Fe}$ and Co complexes showing magnetic properties. Mol. Cryst. Liq. Cryst. 376 (2002) 519-524.

[44] Pillet, S.; Souhassou, M.; Lecomte, C.; Mathonière, C.: Electron density distribution of an oxamato bridged $\mathrm{Mn}$ (II)-Cu(II) bimetallic chain and correlation to magnetic properties. J. Am. Chem. Soc. 126 (2004) 1219-1228.

[45] Ziessel, R.; Stroh, C.; Heise, H.; Kohler, F. H.; Turek, P.; Claiser, N.; Souhassou, M.; Lecomte, C.: Strong exchange Interactions between two radicals attached to non aromatic spacers deduced from Magnetic, EPR, NMR and Electron Density Measurements. J. Amer. Chem. Soc. 126 (2004) 12604-12613.

[46] Pillet, S.; Souhassou, M.; Pontillon, Y.; Caneschi, A.; Gatteschi, D.; Lecomte, C.: Investigation of magnetic interaction pathways by experimental electron density: application to an organic free radical, p-(methylthio)phenyl nitronyl nitroxide. New J. Chem. 1 (2001) 131-143.

[47] Claiser, N.; Souhassou, M.; Lecomte, C.: Problems in experimental charge density modelling of rare earth atom complexes: the case of gadolinium. J. Phys. Chem. Solids 65 (2004) 19271933.

[48] Pillet, S.; Souhassou, M.; Lecomte, C.: Electron density studies of molecular magnetic materials. Acta Cryst. A60 (2004) 455464.

[49] Baron, V.; Gillon, B.; Cousson, A.; Mathonière, C.; Kahn, O.; Grand, A.; Ohrström, L; Delley, B.; Bonnet, M.; Boucherle, J. X.: Spin density maps for the ferrimagnetic chain compound $\mathrm{MnCu}$ (pba) $(\mathrm{H} 2 \mathrm{O})_{3} \cdot 2 \mathrm{H}_{2} \mathrm{O}$. Polarized neutron diffraction and theoretical studies. J. Am. Chem. Soc. 119 (1997) 3500-3506.

[50] Kahn, O.; Mathonière, C.; Shrimivasan, B.; Gillon, B.; Baron, V.; Grand, A.; Ohrström, L.; Ramashasha, S.: Spin distributions in antiferromagnetically $\mathrm{Mn}^{2+}-\mathrm{Cu}^{2+}$ systems. New. J. Chem. 21 (1997) 1037-1045.

[51] Holladay, A.; Leung, P.; Coppens, P.: Acta Cryst. A39 (1983) 377.

[52] Güttlich, P.; Hansen, A.; Spiering, H.: Thermal and optical switching of iron II complexes. Angew. Chem., Int. Ed. Engl. 33 (1994) 2024-2054.

[53] Güttlich, P.; Garcia, Y.; Woike, T.: Photoswitchable coordination compounds. Coord. Chem. Rev. 219-221 (2001) 839-879.

[54] Chen, L. X.: Taking snapshots of photoexcited molecules in disordered media by using pulsed synchrotron X-rays. Angew. Chem., Int. Ed. Engl. 43 (2004) 2886-2905.

[55] Kusz, J.; Spiering, H.; Güttlich, P.: X-ray study of the light-induced metastable state of a spin-crossover compound. J. Appl. Cryst. 33 (2000) 201-205.

[56] Pillet, S.; Hubsch, J.; Lecomte, C.: Single crystal diffraction analysis of the thermal spin conversion of $\left[\mathrm{Fe}(\mathrm{btr})_{2}(\mathrm{NCS})_{2}\right] \mathrm{H}_{2} \mathrm{O}$ : evidence of spin like domains. Eur. Phys. J. B38 (2004) 455-464.

[57] Legrand, V.; Pillet, S.; Souhassou M., Lecomte, C.: Crystallographic study and charge density analysis of photo induced excited states. European Charge Density meeting, ECDMIII. Sanderg, Aarhus Univ. Danmark, June 2003.

[58] Marchivie, M.; Guionneau, P.; Létard, J. F.; Chasseau, D.: Towards direct correlations between spin-crossover and structural features in iron II complexes. Acta Cryst. B59 (2003) 479-486.

[59] Muzet, N.; Guillot, B.; Jelsch, C.; Howard, E.; Lecomte, C.: Electrostatic complementarity in an aldose reductase complex from ultra-high-resolution crystallography and first-principles calculations. Proc. Nat. Acad. Sci. U.S.A. 100 (2003) 87428747.

[60] Schmidt, A.; Jelsch, C.; Rypniewski, W.; Lamzin V. S.: Trypsin revisited: crystallography at (sub)atomic resolution and quantum chemistry revealing details of catalysis. J. Biol. Chem. 10 (2003) 1074. 
[61] Housset, D.; Benabicha, F.; Pichon-Pesme, V.; Jelsch, C.; Maierhofer, A.; David, S.; Fontecilla-Camps, J. C.; Towards the charge density of proteins: a scorpion toxin at 0.96 A resolution as a first test case. Acta Cryst. D 56 (2000) 151-160.

[62] Jelsch, C.; Teeter, M. M.; Lamzin, V.; Pichon-Pesme, V.; Blessing, R. H.; Lecomte, C.: Accurate protein crystallography at ultra-high resolution: valence electron distribution in crambin. Proc. Nat. Acad. Sci. U.S.A. 97 (2000) 3171-3176.

[63] Soler, J. M.; Artacho, E.; Gale, J. D.; Garcia, A.; Junquera, J.; Ordejon, P.; Sanchez-Portal, D.: The SIESTA method for ab initio order-N materials simulation. J. Phys. Cond. Matter. 14 (2002) 2745-2779.

[64] Fernandez-Serra, M. V.; Junquera, J.; Jelsch, C.; Lecomte, C.; Artacho, E.: Electron density in the peptide bonds of crambin. Solid State Comm. 116 (2000) 395-400.

[65] Dauter, Z.; Lamzin, V. S.; Wilson, K. S.: The benefit of atomic resolution. Curr. Opin. Struct. Biol. 7 (1997) 681-688.

[66] Longhi, S.; Czjzek, M.; Cambillau, C.: Messages from ultrahigh resolution crystal structures. Curr. Opin. Struct. Biol. 8 (1998) 730-737.

[67] Dauter, Z.; Lamzin, V. S.; Wilson, K. S.: Proteins at atomic resolution. Curr. Opin. Struct. Biol. 5 (1995) 784-790.

[68] Lecomte, C.; Guillot, B.; Muzet, N.; Pichon-Pesme, V.; Jelsch, C.: Ultra-high resolution X-ray structure of proteins. Cell. Mol. Life Science 61 (2004) 774-782.

[69] Cachau, R.; Howard, E.; Barth, P.; Mitschler, A.; Chevrier, B.; Lamour, V.; Joachimiak, A.; Sanishvili, R.; Van Zandt, M.; Sibley, E.; Moras, D.; Podjarny, A.: Model of the catalytic mechanism of human aldose reductase based on quantum chemical calculations. Journal de Physique 10 (2000) 3-13.

[70] Pichon-Pesme, V.; Lecomte, C.; Lachekar, H.: On building a databank of transferable experimental electron density para- meters: application to polypeptides. J. Phys. Chem. 99 (1995) 6242-6250.

[71] Koritsanszky, T.; Volkov, A.; Coppens, P.: Aspherical atoms scattering factors from wave functions. I. Transferability and conformation dependence of atomic electron densities of peptides within the multipole formalism. Acta Cryst. A58 (2002) 464-472.

[72] Pichon-Pesme, V.; Jelsch, C.; Guillot, B.; Lecomte, C.: A comparison between experimental and theoretical aspherical-atom scattering factors for charge density refinement of large molecules. Acta Cryst. A60 (2004) 204-208.

[73] Jelsch, C.; Guillot, B.; Lagoutte, A.; Lecomte, C.: Advances in protein and small molecules charge density refinement methods using software MoPro. J. Appl. Crystallogr. 38 (2005) 38-54.

[74] Podjarny, A.; Cachau, R. E.; Schneider, T.; Van Zandt, M.; Joachimiak, A.: Subatomic and atomic crystallographic studies of aldose reductase: implications for inhibitor binding. Cell. Mol. Life Science 61 (2004) 763-773.

[75] Guillot, B.; Muzet, N.; Artacho, E.; Lecomte, C.; Jelsch, C.: Experimental and theoretical electron density studies in large molecules: NAD+, beta-nicotinamide adenine dinucleotide. J. Phys. Chem. B107 (2003) 9109-9121.

[76] Rousse, A.; Rischel, C.; Fourmaux, S.; Uschmann, I.; Sebban, S.; Grillon, G., Balcore, Ph.; Förster, E.; Geindre, J. P.; Audebert, P.; Gauthier, J. C.; Hulin, D.: Non thermal melting in semiconductors measured at femtosecond resolution. Nature $\mathbf{4 1 0}$ (2001) 65-68.

[77] Collet, E.; Lemie-Cailleau, M. H.; Buron-Le Cointe.; Cailleau, H.; Wulff, M.; Luty, T.; Koshibara, S. Y.; Meyer, M.; Toupet, L.; Rabiller P.; Teckert S.: Laser induced ferroelectric structural order in an organic charge transfer crystal. Science 300 (2003) 612-615. 